Academic Entrepreneurship for Medical and Health Scientists • Academic Entrepreneurship for Medical and Health Sciences

\title{
Forming and Maintaining Meaningful Partnerships Between Academic Scientists and Corporations
}

Joy Sun ${ }^{1}$, Flaura Winston ${ }^{2}$

${ }^{1}$ Capital One,

${ }^{2}$ MD, PhD; Children's Hospital of Philadelphia | Perelman School of Medicine, University of Pennsylvania

Published on: Sep 23, 2019

DOI: $10.21428 /$ b2e239dc.1afea4ac

License: Creative Commons Attribution-NonCommercial-NoDerivatives 4.0 International License (CC-BY-NC-ND 4.0). 


\section{Topic Relevance by Timeline}

\section{Summary}

- Create "neutral space" opportunities, such as consortia and meetings, allowing for fruitful interactions.

- Protect the interests of all parties to ensure that academics can remain a credible source free from bias.

- Find and establish partnerships through corporate or government information "gatekeepers" and internal influencers.

- Work collaboratively to create a logic model to clarify shared goals and document the partnership's objectives, success metrics, expectations, and timeline.

- Prior to committing to work together, anticipate potential problems and challenges in the partnership and, if the partnership proceeds, develop strategies to resolve issues.

- Start small: confirm and establish a framework for engagement by implementing short-term projects and goals.

\section{Introduction}

For academics desiring to make a broad impact on health and wellness through new products and services, collaboration with corporations is often necessary. This chapter will provide basic guidelines and helpful tips on how academics can form meaningful and successful partnerships with non-academic organizations and corporations. For the purposes of this chapter, the term "academic" is used for anyone within academia interested in working or collaborating with non-academic organizations and will be used interchangeably with the term "academic entrepreneur."

Academics can derive many benefits from industry-academic partnerships. In a typical partnership, the academic entrepreneur designs prototypes and conducts fundamental, formative, and evaluative research. The commercialization partner provides complementary activities, including raising capital, "ruggedizing" prototypes, and 
delivering a product or service at scale. Ruggedizing prototypes is the process by which products are built to resist wear, stress, and other factors that could degrade reliable, consistent performance and is thus necessary to ensuring a commercialgrade, high-quality product. Learning how products perform when delivered at scale can identify new areas for research for the academic and can provide strong validation for the scientific foundation underlying the product.

Academic organizations are often limited in their commercialization activities because these institutions: 1) may not have sufficient resources and expertise in commercialization; 2) might not have the capability or capacity to deliver at scale and provide customer support; or 3) might be subject to taxation for "unrelated business income". Unrelated business income is a trade or business that is regularly carried on and is not substantially related to the purpose of the organization for which it received its exemption from taxation (Internal Revenue Service). This is relevant for most nonprofit organizations, including academic organizations, as they are categorized as 501(c)(3), under Title 26 of the United States Code. Their exempt status must fall within "charitable, religious, educational, scientific, literary, testing for public safety, fostering national or international amateur sports competition, and preventing cruelty to children or animals," excluding sales or commercialization of a product. A partnership with a commercial entity, when done correctly, can be mutually beneficial: the academic or non-profit entity can restrict activities to science, education, and medical care while the commercial entity can bring the resultant, excellent products to society at scale.

\section{Mutually Beneficial Partnerships}

The most important thing to keep in mind is that partnerships must be mutually beneficial. Ideally, all parties in a partnership will share a long-term goal and respect the complementary expertise that each brings to the table. Just as the academic partner should respect the corporate partner's expertise in commercialization, the corporate partner should respect the unbiased, credible research methods, analysis, and interpretations that are expected of the academic partner. Two of the safest ways to ensure that these roles are protected are through: 1) corporate-sponsored research, managed through the academic institution, including language regarding the right to publish, and 2) research funded via a corporate-sponsored consortium (e.g., National Science Foundation Industry-University Cooperative Research Centers). Industryacademic consortiums seek ideas from the company partners and academic faculty, 
who can provide the research priorities, as well. Projects for the consortiums are selected by a panel made up of industry representatives, the funders of these projects, with strong guidance from the Director of the consortium to preserve the perspective of the scientists.

Five key considerations underscore a mutually beneficial academic-industry partnership (Figure 1): 1) create a mechanism for establishing a neutral space through which each party's interests are heard and served, credibility and lack of bias are maintained, and processes are in place to resolve conflicts; 2) identify and connect with corporate "gatekeepers," those who are respected, influential, and connected to others in their corporation, particularly the leadership; 3) formalize the collaboration, utilizing a logic model in which their goals, expectations (e.g., promised resources), and target metrics for success are articulated; 4) identify potential challenges to the relationship and how they will be handled; and 5) memorialize agreements within a mutually beneficial framework for engagement to track decisions and intellectual property.

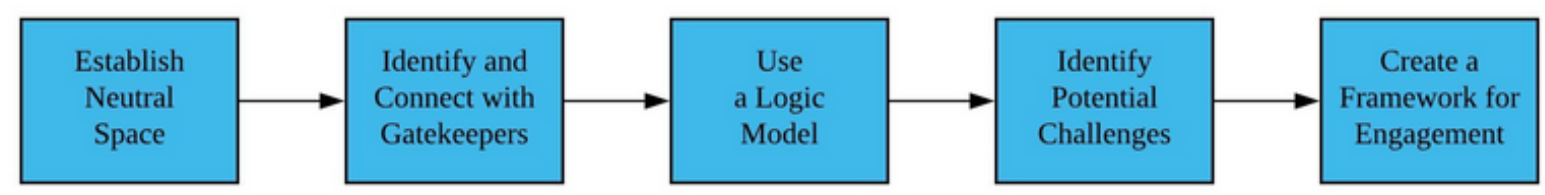

Figure 1

Considerations for a Mutually Beneficial Academic-Industry Partnership.

\section{Creating a Neutral Space}

While both corporate and academic partners may share the same long-term goal (e.g., saving lives, curing cancer), meeting business objectives may require marketing, endorsements, pivots, or methods that do not align with the academic partner's objectives. Likewise, the academic partner's objectives may not be in the interest of the industry partner. For example, while both may want the insights derived from the academic's research, only the academic has the additional obligation to publish the research results. Often, corporations will settle for less certainty, complexity, or precision in results and insights than is acceptable in academia. In addition, university policies that govern the academic's conduct of research (e.g., regarding conflicts of interest and human subjects protection) might be more conservative than those of the industry partner. Thus, two strategies for protecting the interests of all members of an 
industry-university partnership include: 1) employing a neutral third party (e.g., a data oversight board or an impartial reviewer), or 2) funding the work through a consortium model with bylaws and accountability. For the academic entrepreneur, the key concept behind both of these strategies is that priority is given to guaranteeing that the academic can maintain their reputation as a credible, independent scientist and a source free from bias.

The first step to creating a mutually beneficial partnership is to identify where conflicts might arise. For these conflicts, it will be important to remain impartial and highly factual in presentations, ensure impeccable data methods, and limit the provision of opinions or over-interpretation of results. In this way, the academic remains true to the science, neutral about the results, and can continue to be seen as a trusted expert. The data then becomes a neutral foundation on which the partner (including the academic) who receives the information can independently derive their interpretations. Such a data-driven, neutral "space" prevents any one member of a collaboration from gaining more power or influence than another. By creating this neutral space, one will be able to have multiple companies in one room, despite the fact that they may be direct competitors in the marketplace.

A consortium model is an organized collaboration among multiple individuals, companies, or governments with the intention of working toward a chosen objective (. Ranga and Etzkowitz; Mueller and Geddes; Etzkowitz; Grant et al.; Lee et al.). The consortium will provide a structured framework and guidelines to make sure that an academic-commercial partnership can move forward in the interests of both parties. A relevant example of a consortium is the Institute for Food Safety and Health (IFSH), a research consortium consisting of the Illinois Institute of Technology (IIT), the United States Food and Drug Administration's Center for Food Safety and Applied Nutrition (FDA CFSAN), along with other members of the food industry.

The academic should take into account their stature in the field when considering the nature of the industry-university partnerships into which they enter. If the academic is senior, they can afford to not only conduct research on a topic, but also provide controversial opinions based on that research (e.g., when the National Academy of Medicine reviewed and recommended changes to reduce the frequency of mammography screening) while continuing to preserve relationships with partners. On the other hand, more junior faculty members should consider building a strong scientific foundation and gaining credibility in the field before espousing controversial positions, as this advocacy, while important, might limit their recognition as an 
unbiased scholar. The academic entrepreneur, regardless of stature in the field, must recognize their conflicts when conducting research, analyzing data, or drawing conclusions, as they may have a perceived financial interest in the findings. In this case, they may need to isolate themselves from contact with participants or their data and appoint a non-conflicted principal investigator to oversee the conduct of the research and the analyses. Bias is an issue that any academic can face regardless of their role because all academics must abide by university policy and promotion expectations (see the chapter "The Promotion Process: Academic Entrepreneurship Career Tracks").

\section{Connecting with Gatekeepers}

By conducting research in a consortium or by implementing safeguards to prevent undue coercion or bias, robust research careers can be built on corporate-sponsored research. However, an important step is to build the relationship, not to talk about bias. Typically, this will happen in settings in which academics present their work to potential representatives of the commercial entity, the gatekeepers, who attend to bring insights back to the corporation and network. One can identify gatekeepers by the types of discussions they have, as well as by the questions they ask. They are not trying to sell anything; they are trying to learn. For example, they would typically attend scientific meeting presentations rather than place themselves in the exhibit hall. Gatekeepers also maintain extensive networks within the corporation and relationships with corporation leadership in order to share the information they gather. Therefore, these people are influential and can open doors for academics. For academics who want to be on the cutting edge of biotechnology and other technology, they must attend and present, not only at academic meetings, but also at key trade conferences, government-sponsored meetings, and industry-sponsored topical summits, because gatekeepers might reveal the direction in which the company is headed or showcase new innovations and inventions. These events are ideal opportunities for academics to network with those who can commercialize their science and engineering research and also gain access to the latest technology to ensure that their research remains cutting edge (see the chapter "Intellectual Property: Commercializing in a University Setting"). Within each industry, one can attend several conferences at any given time of the year. For example, within the field of biotechnology, there are annual conferences, such as the Business of Biotech Conference and the Global Congress on Biotechnology. Additional examples of 
conferences relating to biotechnology and medical devices can be found in the

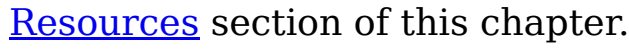

In general, the ideal gatekeeper is someone who has easy access to both interested academics and members at the top of a corporate hierarchy. Gatekeepers may not have direct access to significant financial resources within a company, but if they are impressed by an idea, they can introduce academic partners to people in the company who do have access. Compared to other members of a company, gatekeepers are approachable, because they must actively seek out interested academics to form new partnerships. Moreover, gatekeepers can obtain many benefits by ensuring that they provide cutting edge academic research to the company to inform product development. In essence, gatekeepers are knowledge managers and matchmakers, bringing the right information and people together to advance discovery. Because academics and gatekeepers can mutually benefit from connecting with each other, meeting with gatekeepers is an ideal first step when starting a conversation about a commercialization idea, but one must recognize that while this person might be friendly, their job is to bring insights back to the corporation. The gatekeeper will be a good sounding board for an idea and will be able to maximize chances for success. Unlike the anonymous federal grant review processes, if a sincere, mutual respect is developed with the gatekeeper, they may be likely to review a project proposal and documents before they are communicated with an executive who has access to the budget. Keep in mind, however, that gatekeepers serve as scouts for expertise, talent, ideas, emerging issues, and acquiring assets for corporations, so be sure to protect intellectual property or ideas; keep initial discussions high-level, and be sure, once more details are disclosed, to have a nondisclosure agreement (NDA) in place. 


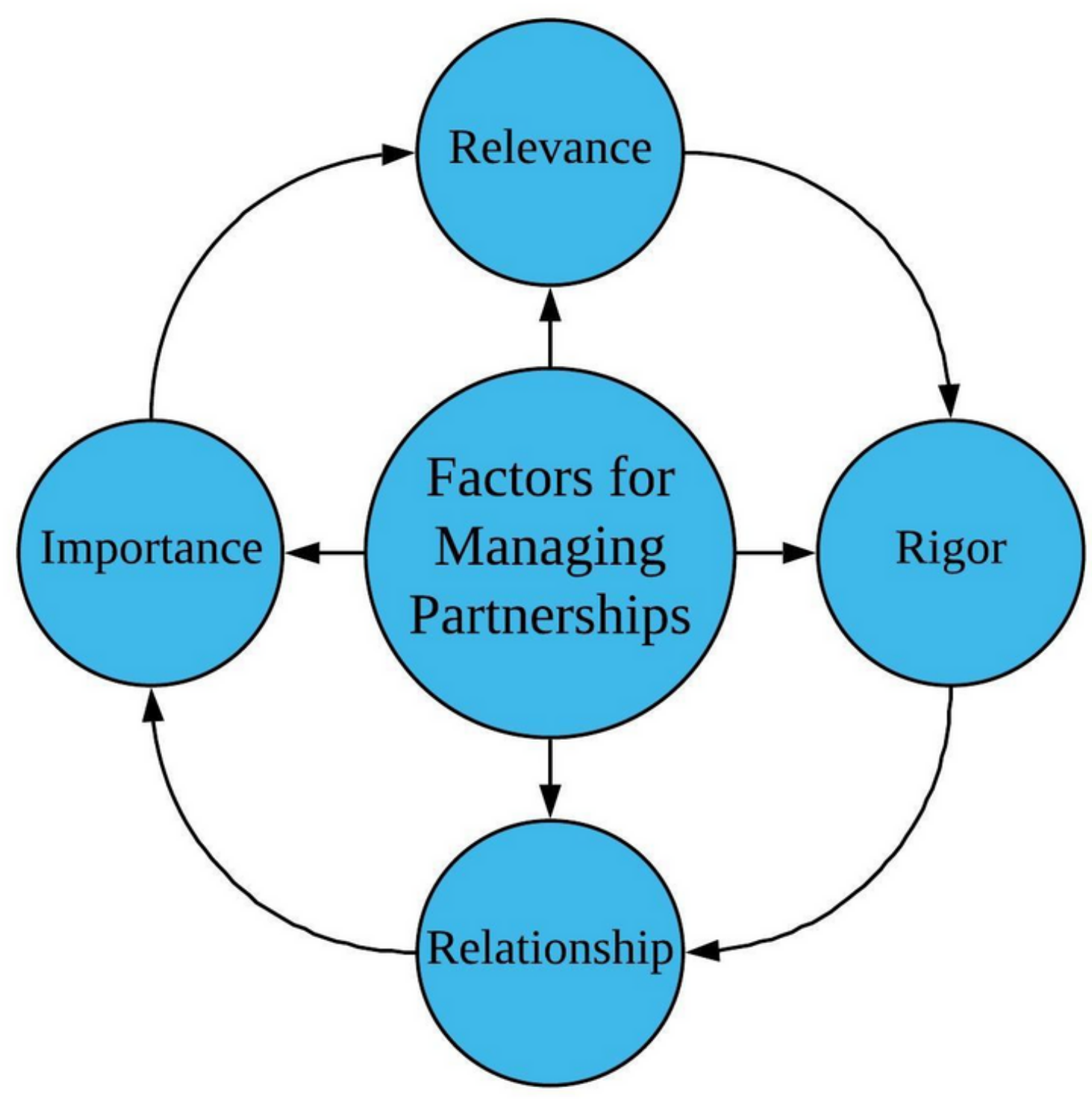

Figure 2

Factors for Managing a Partnership.

When managing the partnership (Figure 2), the academic might think about three R's and I: relevance, rigor, relationship, and importance. These factors, coined by Dr.

Flaura Winston's team as RRRI, represent the key to obtaining funding for research. To gain interest, demonstrate the relevance of the proposed work to the corporate sponsor and the academic's capability to conduct rigorous and thorough research. Keep in mind, this proposed work may be different from the relevance to the field. The 
relevance and rigor give them confidence that a strong relationship of mutual benefit and respect will ensue. The amount of funding given to the project, along with the timeliness of the approval process, are directly related to how important the proposal is perceived to be. Just as an academic will prepare for a federal proposal by reading a request for proposals, when preparing for a corporate-sponsored proposal, one must read and understand the sponsor's needs and goals. If the organization's and the academic's goals are dissimilar, then many of the academic's goals might be considered irrelevant to the organization and vice versa. The academic should spot these signs and discuss with the organization accordingly to avoid any conflicts in the future.

\section{The Logic Model}

Once an interested gatekeeper has agreed to begin a collaboration, the next step is to create a structured and organized plan to accomplish the intended goal. One method for creating a plan is through the use of a logic model. A logic model is a series of "ifthen" steps that link the partnership activities to shared intermediate outcomes and, eventually, to the ultimate end goal. This is a formal way to articulate the shared vision of the collaboration and can be used in both the planning and the implementation stages. The simplest type of logic model contains four components: inputs, activities, outputs, and outcomes (igure 3). These "steps" appear in chronological order; however, during the planning stages, working backward is imperative. Thus, the first step would be to determine the outcome, which makes planning the earlier steps much easier. All parties should identify and agree on the ultimate, long-term goal with measurable, time-limited impact success metrics. Next, they should work backward to define intermediate goals, outline steps to achieve these goals, and define process metrics, which is how the partnership will ensure that the proposed work is on track. Partners should agree on short-term goals, as well. To reach an outcome, a series of activities must produce measurable output (for example, completing data collection or building a prototype). The inputs are raw materials, the people and environment, the scientific foundation, and the capital required to perform an activity. Utilizing a logic model planning process helps to articulate a "compass" or direction for the partnership, which ensures a common understanding of what resources will be provided, what work will be accomplished, and what goals will be achieved over what time period. Creating a logic model is best done in person with all parties present in 
order to ensure that neutral space is maintained and that all parties are aware and in agreement with the plan.

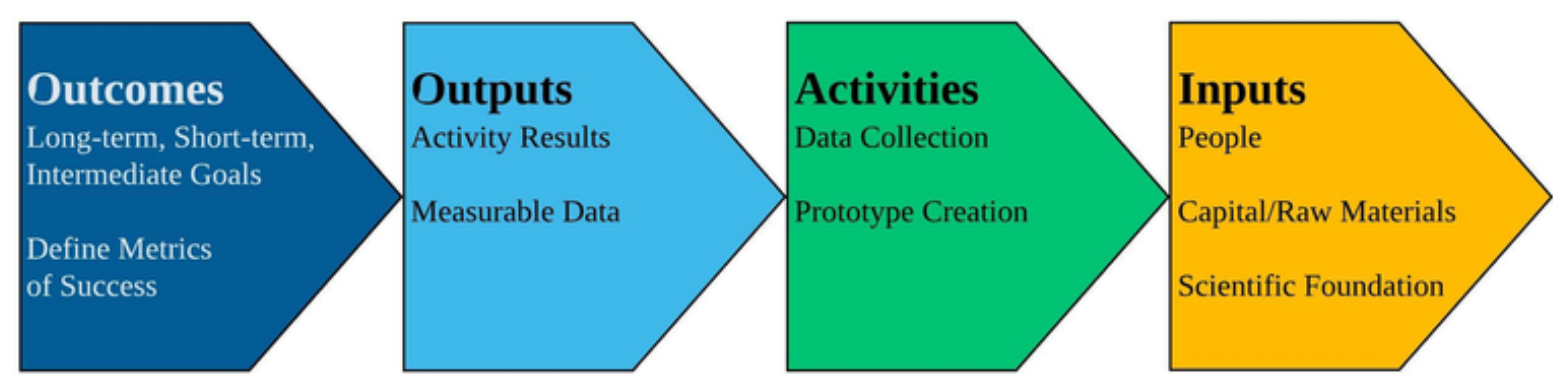

Figure 3

Backwards Logic Model.

\section{Identifying Potential Challenges}

A key component of the logic model planning process is to identify barriers and challenges and how these will be overcome. Doing this in advance, when everyone is excited about the project, will provide a starting point for strategies to resolve challenges when they inevitably arise and when stress may preclude clear thinking. All of this, however, builds on the foundation of a relationship and mutual respect for the challenges and goals that each party holds.

For complex relationships, in addition to a contract, a Memorandum of Understanding might help to govern daily, weekly, and less frequent communication, sharing of data and resources, and other potentially challenging issues. The logic model also helps to avert challenges and misunderstandings by confirming: 1) that business objectives align with scientific objectives, and 2) how success will be measured. An organization and academic must mutually decide and agree upon certain questions before beginning their partnership: what are the metrics of success in accomplishing a goal, and what will happen if the success metrics are not reached? What will be the implication for each of the parties and for the partnership? The answer to these questions varies based on the objectives of both the researchers and the business organizations. Often the challenges arise from misunderstandings, resulting from scientific or business jargon, along with cultural differences between academics and corporations. From the start, keep an open line of communication whereby any concerns can be discussed and rectified. Discussing details of ownership upfront before wasting time in negotiations about the core elements of an arrangement is also 
important. The academic partner should secure their "freedom to publish" in order to allow academic productivity and clarify intellectual property (IP) relations by securing ownership of findings; this involves including explicit language in contracts and sponsored research agreements to preserve these rights. (see the chapters "Intellectual Property: Ownership and Protection in a University_Setting" and "Intellectual Property: Commercializing in a University_Setting"). This final point should be explicitly determined within a partnership, as both parties will be providing data and research that is not available to the public. Typically, a partnership involves obtaining early access to data, or exclusive access to data or resources. For example, through collaboration with original equipment manufacturers and restraint suppliers in the auto industry, Dr. Flaura Winston and colleagues have access to the next generation of safety technology, real-time licensing data, and alerts of insurance claims and police reports for crashes as sources that fuel their research. Special care must be taken to preserve confidentiality and to protect trade secrets, as required by law and agreement with the organization.

Corporate-sponsored research provides the diversity in funding that is necessary to manage the precariousness of federal funding and the long lags between proposal submission and the awarding of funds, which, in the fast-paced technology world, could render research obsolete by the time it is conducted, analyzed, and published. Let the corporate sponsor know that the academic has the intention to submit proposals for multiple sources of funding. This point will likely need to be negotiated as the corporate sponsor will have rights to the results and might want to limit, at least in time, the submission of follow-on funding. Regardless, an excellent academiccorporate relationship might provide high-risk funding investments to federal agencies or applied research that does not advance scientific paradigms. Federal agencies, which are subject to review by anonymous scientific review committees, might be given the approval to recommend funding for these high-risk investments (e.g., new ideas without feasibility data), but other sources of funding should be considered for time-sensitive research. Alternatively, there are also risks for commercial funding, such as conflicts of interest or a funder claiming IP rights. (see the chapter "Understanding Conflict of Interest for Academic Entrepreneurs"). Diverse funding can be favorable, as long as academic entrepreneurs have a strong publication record. 


\section{Framework for Engagement}

Finally, ensure that a framework for engagement is established (Figure 4).

Partnerships should ultimately be treated like a marriage; all attempts should be made for equal rights the relationship should first be tested before fully committing.

Conducting a small trial or short-term project first is an effective way to determine whether the partnership will succeed or fail. This short-term project is especially useful to learn if mutually agreed upon aspects of time and communication are present in the partnership. This is vital if the end goal of a partnership is to conduct a longterm or intensive project. In addition, honesty and respect are paramount: for example, personal goals, such as the requirements for academic promotion should be described. Academic motives are not necessarily more pure than industrial motives and should not be seen as such; both parties, if respect is preserved, should value the other's needs and challenges, and the motives of both the academic and industrial entities need to align with long-term goals of the partnership. If these motives are not aligned initially, the commercial company could force the academic partners in a direction they do not want to go in order to continue to receive funding or access to technology. This misstep can be prevented by making sure that multiple metrics are laid out, such as one, two, and five year goals. Defining these metrics can help ensure success. If the commercial company starts controlling the relationship, the relationship will become more short-term and replaceable once they have the information they need from the academic entity, which can be very stressful for the academics. 


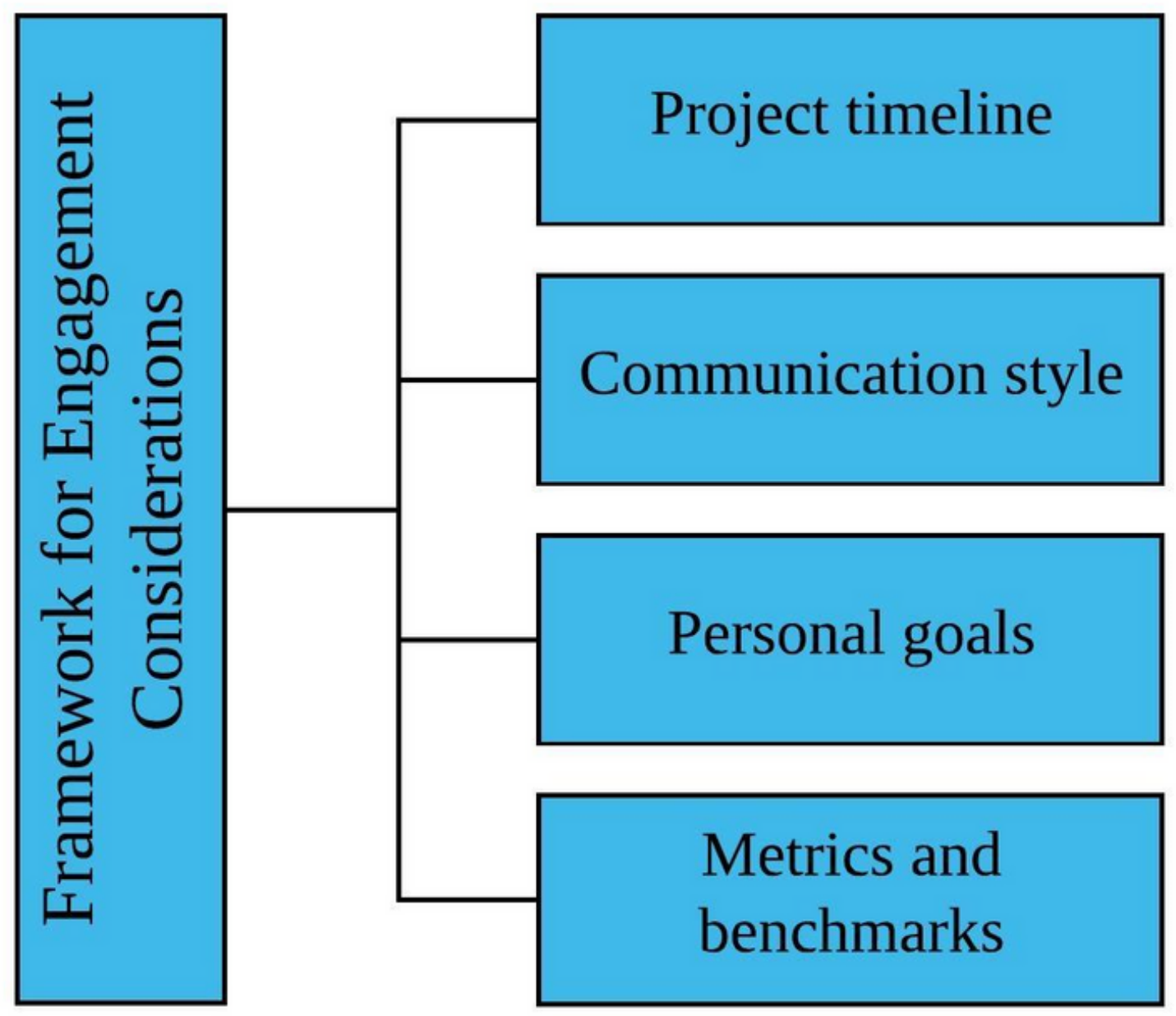

Figure 4

Framework for Engagement Considerations.

\section{Conclusion}

This chapter presents aspects of a mutually beneficial partnership, how to create a neutral space, how to make connections with organizations through gatekeepers, the basics of the logic model, the considerations all parties of potential partnerships must discuss prior to beginning the relationship, and the importance of establishing a framework for engagement. Partnerships are most successful when they are mutually beneficial, which encourages all parties to invest enough resources to succeed. A neutral space can be beneficial for gathering insight from several major competitors at once and prevents bias. Gatekeepers are key to finding connections to an organization 
and are interested in seeking out potential relationships with academic entrepreneurs. The logic model can be used to clearly form a timeline and set of goals for the partnership, as challenges must be discussed prior to beginning the partnership in order to maximize success. Finally, a framework for engagement is the most efficient method for creating a strong and successful partnership. Like any other relationship, communication is the key to a successful partnership. Establish trust by openly communicating goals and interests, and collaborators may be more inclined to reciprocate. Building partnerships to solve difficult problems can be a challenge. Correctly forming one, however, can ultimately be beneficial for both individuals and for society as a whole.

\section{Resources}

Managing the Industry/University_Cooperative Research Center: A Guide for Directors and Other Stakeholders

- Managing the Industry/University Cooperative Research Center: A Guide for Directors and Other Stakeholders was written and edited by Denis O. Gray and S. George Walters as a guide to help plan and implement cooperative research.

\section{Cooperative Research Centers and Technical Innovation}

- The book Cooperative Research Centers and Technical Innovation written by Denis O. Gray, Craig Boardman, and Drew Rivers provides a good discussion of intermediary organizations as a tool to facilitate cooperation between businesses and other organization in the chapter "The New Science and Engineering Management: Cooperative Research Centers as Intermediary Organizations for Government Policies and Industry Strategies" on pp. 3-33.

\section{Biotech Conferences to Attend in 2018}

- The article on AppFluence "17 Biotech Conferences to Attend in 2018" provides an example of various conferences surrounding biotechnology that will occur in 2018. As most conferences are annual, this article may be used as a reference for future conferences as well.

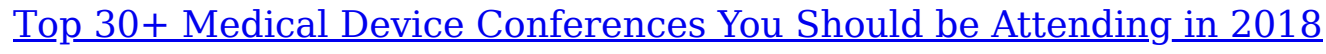


- This article on Greenlight Guru "Top 30+ Medical Device Conferences You Should be Attending in 2018" discusses the various conferences occurring in 2018 revolving around medical devices. As most conferences are annual, this article may be used as a reference for future conferences as well.

The Cardiac Safety Research Consortium enters its second decade: An invitation to participate

- This article in ScienceDirect entitled "The Cardiac Safety Research Consortium enters its second decade: An invitation to participate" provides an overview of the formation and history of the Cardiac Safety Research Consortium after its first decade in operation and provides a model for other groups starting to develop similar collaborative forums.

W.K. Kellogg_Foundation Logic Model Development Guide

- This guide to building logic models was developed to help organizations plan outcome-oriented programs with an eye for demonstrating effectiveness.

The contents of this chapter represent the opinions of the chapter authors and editors. The contents should not be construed as legal advice. The contents do not necessarily represent the official views of any affiliated organizations, partner organizations, or sponsors. For programs or organizations mentioned in this chapter, the authors encourage the reader to directly contact the relevant organization for additional information.

\section{Citations}

1. Internal Revenue Service. Exempt Purposes Internal Revenue Code Section 501c3 / Internal Revenue Service. 13 May 2019, https://www.irs.gov/charities-nonprofits/charitable-organizations/exempt-purposes-internal-revenue-code-section$\underline{501 \mathrm{c} 3} . \pm$

2. Ranga, Marina, and Henry Etzkowitz. "Triple Helix Systems: An Analytical Framework for Innovation Policy and Practice in the Knowledge Society." Industry 
and Higher Education, vol. 27, no. 4, SAGE Publications Ltd, Aug. 2013, pp. 237-62, https://doi.org/10.5367/ihe.2013.0165..

3. Mueller, D., and L. A. Geddes. "Industry-University Cooperative Research." Medical Instrumentation, vol. 18, no. 1, Jan. 1984, pp. 72-74, https://www.ncbi.nlm.nih.gov/pubmed/6708854..

4. Etzkowitz, Henry. "Innovation in Innovation: The Triple Helix of UniversityIndustry-Government Relations." Social Sciences Information. Information Sur Les Sciences Sociales, vol. 42, no. 3, SAGE Publications Ltd, Sept. 2003, pp. 293-337, https://doi.org/10.1177/05390184030423002.

5. Grant, Matthew, et al. "Pediatric Medical Device Consortia: A Novel Pathway for Pediatric Device Development for Pediatric Urologists and Other Pediatric Specialists." Urology Practice, vol. 2, no. 4, July 2015, pp. 206-10, https://doi.org/10.1016/j.urpr.2014.11.002.

6. Lee, Chang Ho, et al. "University-Industry Collaboration in a Triple Helix Setting on a US Medical Campus." Industry and Higher Education, vol. 29, no. 1, SAGE Publications Ltd, Feb. 2015, pp. 37-49, https://doi.org/10.5367/ihe.2015.0240. 